\title{
Looking at maternal inequalities (socioeconomic class, age and human immunodeficiency virus status) to predict well-being of neonates during infancy
}

\author{
Baba Usman Ahmadu \\ Department of Paediatrics, Federal Medical Centre, Yola, Nigeria; ahmadu4u2003@yahoo.com \\ Received 4 June 2013; revised 4 July 2013; accepted 22 July 2013 \\ Copyright (C) 2013 Baba Usman Ahmadu. This is an open access article distributed under the Creative Commons Attribution License, \\ which permits unrestricted use, distribution, and reproduction in any medium, provided the original work is properly cited.
}

\begin{abstract}
Background: Infant health inequalities responsible for high infant sicknesses and deaths in our setting could depend to a large extend on maternal inequalities like socioeconomic class (SEC), age and human immunodeficiency virus (HIV). Objective: To look at maternal inequalities (SEC, Age and HIV), to predict well-being of neonates during infancy. Methods: Subjects were selected using systematic random sampling. Maternal education, occupation, age and HIV status were obtained using a questionnaire; their SEC was derived using the Oyedeji's model. Gestational age (GA) of the neonates was estimated from their mother's last menstrual period, obstetric ultrasound scan reports or the Dubowitz criteria; and birthweight (BW) was determined using the basinet weighing scale, which has a sensitivity of $\mathbf{5 0}$ grams. Results: Ninety mother-neonatal pairs were enrolled, 47 $(52.2 \%)$ neonates were males and $43(47.8 \%)$ females. Most of the neonates were term 66 $(73.3 \%)$ and of normal BW 75 (83.4\%). A significant association existed between maternal variables and the likely hood of the subjects being less healthy during infancy $\left(x^{2}=126.528, p<\right.$ $0.005)$. Maternal age had a negative correlation coefficient with GA $(r=-0.200)$ and $B W(r=$ -0.115 ) and comparison of MA, GA and BW was significant $(F=2662.92, p<0.0001)$. Conclusion: The combine effects of maternal SEC, Age and HIV have predicted less healthy neonates during infancy. Neonates in the present work are more prone to sicknesses and ill-health during infancy.
\end{abstract}

Keywords: Maternal (Socioeconomic Class, Age, HIV); Mother-Neonatal Pairs; Infant Health; Maiduguri; Nigeria

\section{INTRODUCTION}

The infant mortality rate in Nigeria is around $98 / 1000$ [1]. Developing countries have 2.4 times higher rate of infant mortality than developed ones [2]. Infant health is influenced by maternal factors such as maternal socioeconomic class (SEC), age and human immunodeficiency (HIV). These factors have enormous public health implications, such as huge medical bills on governments, individuals or health insurance. For instance, the Joint Center for Political and Economic Studies in 2009 reported that medical expenses that included infancy related illnesses costed billions of dollars [3]. Mothers who belong to low SEC are not only more vulnerable to illhealth with high mortality rate; their infants also suffer from diseases that could lead to death. Suthers [4] in 2008 published that hundreds of thousands of children died in infancy from causes that included low maternal SEC. Mothers of low SEC are much prone to social vices like discrimination, isolation which have negative health implications on their infants. More so, Derose and Baker [5] in 2000 found that mothers who cannot communicate effectively have problems utilizing the healthcare services and are more likely to have health needs of their infants like immunization un-attended to.

Maternal age (MA) under thirty has been linked to infant abuses, maltreatment and lack of immunization [6]. Maternal inexperience might be responsible for poor infant health in mothers under thirty years of age. Infants that are HIV exposed are more likely to lose their HIV parents due to medical and socioeconomic inadequacies especially in developing countries like ours. As such, 
these infants are more likely to be nurtured in poverty without adequate nutrition, shelter, safe drinking water, health care services, immunization and proper environmental sanitation $[1,7]$. These factors in our locality constitute a threat to infant's survival because of high disease burden and deaths that are associated with them.

Vast literature reviews showed dearth of information on the triple effect of maternal SEC, age and HIV to predict well being of neonates during infancy especially in developing countries. More so, no such study has been done in Nigeria to the best of my knowledge. This manuscript aimed at: 1) To determine the contributory roles of maternal SEC, age and HIV on babies well-being during infancy based on rational data; 2) To provide relevant public health information regarding babies health during infancy in Maiduguri, Borno state, North-Eastern Nigeria.

\section{MATERIAL AND METHODS}

\subsection{Study Area}

The study was conducted at the Department of Paediatrics and Obstetrics unit of the University of Maiduguri Teaching Hospital, (UMTH), Borno State, Nigeria. Being the largest health facility in the region, the UMTH serves as a referral hospital for six North-Eastern States of Nigeria and neighboring countries of Chad, Cameroon and Niger Republics.

\subsection{Ethical Considerations}

The present study protocol was reviewed and ethical clearance authorized by the Medical Research and Ethics Committee of the UMTH. All work was performed according to the international guidelines for human experimentation in clinical research [8]. Informed consent from parents was also obtained after explaining the purpose and the objectives of the study. Parents had unlimited liberty to deny consent or opt out of the study without any consequences.

\subsection{Sample Size/Subject Selection}

The minimum sample size was determined using statistical formula, which computes four percent crude birth rate for Nigeria at $95 \%$ confidence interval and alpha levels of $0.05[1,7,9]$. This sum up to 60 ; but $50 \%$ of this was added to maximize power. Therefore, the study population consisted of 90 mother-neonatal pairs. Participation in this study was voluntary and consenting pregnant women were selected using systematic random sampling method where the first of every four pregnant woman was picked as they presented to the labor ward. Where the first did not fulfill the inclusion criteria, the immediate next pregnant woman that qualified was se- lected. Pregnant women who had their antenatal care, consented to HIV screening and delivered at the UMTH were eligible to participate in this study. Severely sick pregnant women or those who decline consent for the study were excluded.

Maternal education, occupation, age, HIV status was obtained using a questionnaire from antenatal health records and in some instances from the mothers themselves. Maternal SEC was obtained from educational and occupational attainment of a mother using the Oyedeji's model [10]. Gestational age (GA) of the neonates was determined from their mother's last menstrual period or obstetric ultrasound scan reports or the Dubowitz criteria [11]. Birthweight (BW) of the neonates was measured using the basinet weighing scale that has a sensitivity of 50 grams. Neonates weighing greater than $3.99 \mathrm{~kg}$ were classified as macrosomia, those weighing $2.5-3.99 \mathrm{~kg}$ as normal and those less than $2.5 \mathrm{~kg}$ were low birth weight [12].

\subsection{Statistical Analysis}

Data were expressed as frequencies; mean (SD) and 95\% confidence intervals (CIs). Correlation coefficient of MA with GA and BW was obtained; Chi-square and analysis of variance (ANOVA) were used to investigate categorical and quantitative variables respectively. A p-value $<0.05$ was considered significant. Tables were used for demonstrations. Statistical package for social science (SPSS) statistical software version 16, Illinois, Chicago USA was used for all analysis.

\section{RESULTS}

Of a total of 90 mother-neonatal pairs enrolled in this study, $47(52.2 \%)$ neonates were males and $43(47.8 \%)$ were females, and the male to female ratio is 1.09:1. Most of the neonates were term 66 (73.3\%) and of normal BW 75 (83.4\%) (Table 1). There was significant association between maternal (SEC, Age, HIV) and the likely hood of the neonates being less healthy during infancy $\left(\chi^{2}=126.528, p<0.005\right)$ (Table 2).

Table 3 below shows mean BW, GA and MA of the study group. The mean BW and GA were normal. Maternal age had negative correlation coefficient with GA $(\mathrm{r}=$ $-0.200)$ and $\mathrm{BW}$ of neonates $(\mathrm{r}=-0.115)$ and mean comparison for MA, GA and $\mathrm{BW}$ was significant $(\mathrm{F}=$ $2662.92, \mathrm{p}<0.0001)$.

\section{DISCUSSIONS}

A large number of mothers were in their twenties and belong to low SEC with one-tenth of them having HIV in present study. Poverty level is high among mothers of low SEC, which could lead to sexual exploitation, early pregnancy in addition to being prone to sexually trans- 
mitted diseases like HIV [7]. Similar observation was reported in Lagos, Nigeria, Sudan and other sub-Saharan countries of the world $[1,13]$. Reasons being that higher proportion of mothers are illiterate, not gainfully employed, and are therefore at increased risk of poverty, early pregnancy and HIV.

Most of the neonates that participated in this study are more vulnerable to illnesses going by the prediction of this work. This corroborated findings of Williams [14] in the United States in 2005. Socioeconomic class in most circumstances can predict a person overall health status. Braveman and Egerter [15] in 2008 have highlighted that maternal access to quality healthcare services and prognosis depends on their SEC among other determinants. For instance, low SEC mothers are indigent and are more likely to suffer from ill-health, physical and cognitive defects and deaths arising from inadequate access to

Table 1. Birth characteristics of the neonates.

\begin{tabular}{ccc}
\hline Characteristics & Frequencies & Percentages \\
\hline Sex & & \\
Male & 47 & 52.2 \\
Female & 43 & 47.8 \\
GA & & \\
Preterm & 11 & 12.2 \\
Term & 66 & 73.3 \\
Post-term & 13 & 14.5 \\
BW & & \\
LBW & 12 & 13.3 \\
Normal & 75 & 83.4 \\
Macrosomia & 3 & 3.3 \\
\hline
\end{tabular}

$\mathrm{GA}=$ Gestational age, $\mathrm{BW}=$ Birthweight, $\mathrm{LBW}=$ Low birthweight.

Table 2. Prediction of infant wellness using maternal variables.

\begin{tabular}{ccc}
\hline Maternal variables & N (\%) & Prediction of infant wellness \\
\hline SEC & & $+\mathrm{ve}$ \\
Low & $72(80)$ & $-\mathrm{ve}$ \\
High & $18(20)$ & \\
Age (years) & & $+\mathrm{ve}$ \\
Less than 30 & $75(83.3)$ & $-\mathrm{ve}$ \\
Greater than 30 & $15(16.7)$ & \\
HIV & & $+\mathrm{ve}$ \\
Positive & $9(10)$ & $-\mathrm{ve}$ \\
Negative & $81(90)$ &
\end{tabular}

$\left(\chi^{2}=126.528, \mathrm{p}<0.005\right) ; \mathrm{SEC}=$ Socioeconomic class; HIV $=$ Human Immunodeficiency Virus; +ve = Positive prediction of sickness during infancy (less healthy infants); $-\mathrm{ve}=$ Negative prediction of sickness during infancy (healthy infants).
Table 3. Birthweight, gestational age and maternal age profile of the subjects.

\begin{tabular}{ccc}
\hline Variables & Mean (SD) & 95\% CI \\
\hline BW (kg) & $3.0(0.6)$ & $2.9-3.1$ \\
GA (weeks) & $38.6(2.0)$ & $38.2-39.0$ \\
MA (years) & $23.9(5.3)$ & $22.8-25.0$ \\
\hline
\end{tabular}

$(\mathrm{F}=2662.92, \mathrm{p}<0.0001) ; \mathrm{BW}=$ Birthweight $\mathrm{GA}=$ Gestational age; $\mathrm{MA}=$ Maternal age; $\mathrm{CI}=$ Confidence intervals.

health services and sub-standard health care delivery [15]. Now, if these mothers are sick, their infants are also at risk of being less healthy because of in proper nurturing. Furthermore, low SEC mothers are more likely to be less educated and unemployed. These mothers could experience hunger from malnutrition, environmental inequalities from poor infrastructure like poor housing, inadequate roads and un-safe drinking water [15]. All of which contribute to infants recurrent sicknesses thereby making their overall health outcome poor.

Majority of mothers in current study are less than 30 years old and young age has been associated with poor quality of infants' health [16]. Similar observation was made by Pittard et al. [6] in South Carolina in 2008. Some of the reasons advanced for this are firstly, many unplanned and unregistered pregnancies have been associated with young age. Secondly, pregnancy in younger age has striking psychological, social and physiologic events that could have negative impact on neonates during infancy. For example, young age mothers may not consider it important to have a health seeking behavior for themselves and their infants. Thirdly, infant abuses, maltreatment, lack of immunization and lower income have been reported to be more in infants of young age mothers $[6,16,17]$. All these would contribute to inadequate care of an infant making them highly susceptible to being sick repeatedly during infancy.

In as much as young age could be associated with health inequality in infants, advancing MA also may have a negative impact on infant health [13]. The present study revealed that MA varies indirectly with BW of the neonates. That is to say, with increasing MA, the weight of the neonates reduces. This concurred findings by Eltahir [13] in Sudan in 2008 that could probably be explained by maternal wear and tear due to ageing. Therefore advanced aged mothers are more likely going to give birth to low BW babies, which has been associated with high infant morbidities and mortalities.

Ten percent of the neonates from this study are vulnerable children because they are HIV exposed [1,7]. As such, they are susceptible to recurrent diseases particularly lung infections, malnutrition, intentional and unintentional injuries just to mention a few [7]. The HIV exposed infants stand the risk of being orphans. Studies 
have shown that millions of children are now orphans because of HIV/AIDS, greater of these are resident in sub-saharan Africa $[1,7,18]$. The loss of one or both parents pervades every aspect of an infant's life, their emotional, physical and mental well-being. It deprives infants of their right to parental and family care making them prone to stigmatization and discrimination, which could further predispose them to ill-health.

\section{CONCLUSION}

Young age mothers from low SEC constituted most of the study cohorts and the combine effects of maternal SEC, Age and HIV have predicted less healthy neonates during infancy. In the light of this, neonates from current work are more liable to sicknesses that may impact negatively on their overall health during infancy.

\section{LIMITATION}

This work was a uni-centered study; therefore, caution is needed in generalizing the findings of this study.

\section{RECOMMENDATIONS}

In order to optimize infant health in our environment, there is the need for relevant authorities to implement strategies that will empower women socioeconomically like vocational and skilled acquisition training. These will help increase maternal income that is required to offset hospital bills of both mother and infants. There is also the need for women to be well informed on safe reproductive health practices, which may help them plan towards child up-bringing, prevent wanted pregnancies and contracting HIV. Studies of this kind in the future should include mother-neonatal pairs from multiple health centers in order to have a representative cross-section of the study population.

\section{ACKNOWLEDGEMENTS}

I acknowledge the kind help and encouragement I received from the administrative, medical and nursing staff of the UMTH.

\section{REFERENCES}

[1] World Health Organization (2006) Country health system fact sheet Nigeria. World Health Organization, Geneva.

[2] The Office of Minority Health (2012) Infant mortality and African Americans.

http://minorityhealth.hhs.gov/templates/content.aspx?ID= $\underline{3021}$

[3] Joint Center for Political and Economic Studies (2012) The economic burden of health inequalities in the United States.

http://www.jointcenter.org/hpi/sites/all/files/Burden_Of Health FINAL 0.pdf
[4] Suthers, K. (2012) evaluating the economic causes and consequences of racial and ethnic health disparities. http://www.apha.org/NR/rdonlyres/EF3D92F8-4758-4E4 9-85A1-D6EB8AD8CA89/0/Econ2 Disparities Final.pd $\underline{\mathrm{f}}$

[5] Derose, K.P. and Baker, D.W. (2000) Limited English proficiency and Latinos' use of physician services. Medical Care Research and Review. http://mcr.sagepub.com/content/57/1/76.full.pdf+html

[6] Pittard, W.B., Laditka, J.N. and Laditka, S.B. (2008) Associations between maternal age and infant health outcomes among medicaid-insured infants in South Carolina: Mediating effects of socioeconomic factors. Pediatrics, 122, 100-106.

[7] UNICEF (2005) The state of the World's children. UNICEF, New York.

[8] World Medical Association Declaration of Helsinki (2005) Ethical principles for medical research involving human subjects, 2000. World Medical Association.

http://www.wma.net/e/policy/b3.htm

[9] Naing, L., Winn, T. and Rusli, B.N. (2006) Practical issues in calculating the sample size for prevalence studies. Archives of Orofacial Sciences, 1, 9-14.

[10] Oyedeji, G.A. (1985) Socio-economic and cultural background of hospitalised children in Illesha. Nigerian Journal of Paediatrics, 12, 111-117.

[11] Dubowitz, L., Dubowitz, V. and Goldberg, C. (1970) Clinical assessment of gestational age in the newborn infant. Journal of Pediatrics, 77, 1-10.

[12] Uche, N. (2007) Assessment and care of the newborn. In: Azubuike, J.C. and Nkanginieme, K.E., Eds. Pediatrics and Child Health in a Tropical Region, 2nd Edition, African Educational Services, Owerri, 163-177.

[13] Eltahir, M.E. and Gerd, S. (2008) The effect of maternal anthropometric characteristics and social factors on gestational age and birth weight in Sudanese newborn infants. BMC Public Health, 8, 244-253.

[14] Williams, D.R. (2012) The health of US racial and ethnic populations.

[15] Braveman, P. and Egerter, S. (2012) Overcoming obstacles to health.

http://www.rwjf.org/en/research-publications/find-rwjf-re search/2008/02/overcoming-obstacles-to-health.html

[16] Bagge, M.J., Roberts, J.E. and Norr, K.F. (1989) A comparative study of plans for infant care made by adolescent and adult mothers. Journal of Adolescent Health Care, 10, 537-540.

[17] McCarthy, J. and Hardy, J. (1993) Age at first birth. Journal of Research on Adolescence, 3, 373-392.

[18] Joint United Nations Programme on HIV/AIDS, United Nations Children's Fund and the United States Agency for International Development (2004) Children on the brink 2004: A joint report of new orphan estimates and a framework for action, population, health and nutrition project for USAID. Washington DC. 


\section{ABBREVIATIONS}

BW: Birthweight;

CI: Confidence interval;

GA: Gestational age;

HIV: Human immunodeficiency virus;
LBW: Low birthweight;

MA: Maternal age;

SEC: Socioeconomic class;

SD: Standard deviation. 